Original article

\title{
Molecular quantitative assay for esterase-mediated organophosphate resistance in Rhipicephalus microplus
}

\author{
Luciana Gatto Brito ${ }^{\mathrm{a}, *}$, Loui de Oliveira Nery ${ }^{\mathrm{a}}$, Fabio da Silva Barbieri ${ }^{\mathrm{a}}$, Maribel E. Funes Huacca ${ }^{\mathrm{b}}$, \\ Soraya dos Santos Pereira ${ }^{c}$, Renata Reis da Silva ${ }^{a}$, Carla Celedônio de Freitas Fernanades ${ }^{c}$, \\ Márcia Cristina de Sena Oliveira ${ }^{\mathrm{d}}$ \\ a Embrapa Amazônia Oriental, Belém, PA, Brazil \\ b Universidade Federal de Rondônia, Porto Velho, RO, Brazil \\ c Fiocruz Rondônia, Porto Velho, RO, Brazil \\ d Embrapa Pecuária Sudeste, São Carlos, SP, Brazil
}

\section{A R T I C L E I N F O}

\section{Keywords:}

Cattle tick

Organophosphate resistance

Esterases

\begin{abstract}
A B S T R A C T
The use of pesticides is the main tool to control infestations of the cattle tick Rhipicephalus microplus, and organophosphate (OP) is one of the most used compounds for this purpose. Carboxylesterases (ChEs) are targets for OP pesticides in arthropods, and acetylcholinesterase $2\left(\mathrm{AChE}_{2}\right)$ and esterase $1\left(\mathrm{EST}_{1}\right)$ are metabolic enzymes involved in the xenobiotic detoxification process. The increase in the synthesis of these enzymes can be detected by the quantitative polymerase chain reaction (qPCR) assay, which was used to identify cattle tick populations resistant to OP pesticides. For that, two field populations of $R$. microplus were used, one previously identified by the larval packet test (LPT) as OP - sensitive $\left(\mathrm{LC}_{50}=0.13 \mu \mathrm{g} / \mathrm{cm}^{2}\right)$ and the other OP-resistant $\left(\mathrm{LC}_{50}=8.14 \mu \mathrm{g} /\right.$ $\mathrm{cm}^{2}$ ). To promote the OP enzyme detoxification, groups of 10 females of the resistant strain were immersed in solutions of diazinon in technical grade at concentrations of $1.0 \mathrm{mg} / \mathrm{ml}, 2.5 \mathrm{mg} / \mathrm{ml}$, and $5.0 \mathrm{mg} / \mathrm{ml}$. The ticks that survived diazinon exposure were submitted to GPCR assay, which enabled observing an increase in $\mathrm{AChE}_{2}$ and EST $_{1}$ synthesis in the OP-resistant strain when compared to the susceptible strain. The initial results of expression analysis suggest that the $\mathrm{QPCR}$ assay can discriminate OP-resistant and susceptible populations. The development and improvement of molecular diagnostic tests to identify pesticide resistant $R$. microplus populations are priorities and in the near future it will be important to expand the molecular targets involved in OP resistance, which could be used for better selection of effective strategies to control cattle tick populations.
\end{abstract}

\section{Introduction}

The cattle tick, Rhipicephalus microplus is an obligate hematophagous ectoparasite that is adapted to climatic conditions in tropical and subtropical regions of the world. The economic importance of $R$. microplus is related to direct damage to their hosts, because heavy tick loads reduce cattle productivity and irreparably damage hides. In addition, this tick is responsible for the transmission of agents of bovine babesiosis and anaplasmosis, important diseases that cause significant economic losses to cattle breeders.

The use of chemical pesticides to control R. microplus ticks still is the most efficient method. However, the indiscriminate and inadequate use of some of them, such as organophosphates (OP), has induced development of resistance in cattle tick populations around the world (Miller et al., 2005; Baffi et al., 2008; Jyoti et al., 2014; Bendele et al., 2015;
Graham et al., 2016; Jyoti et al., 2016; Robbertse et al., 2016). Despite this growing problem of resistance, the use of synthetic pyrethroids (SP) and OP pesticides for control of cattle tick populations in Brazil is very common (Mendes et al., 2011; Brito et al., 2011; Higa et al., 2015).

Many gaps still exist to understand arthropod pesticide resistance, and the xenobiotic metabolism is an important topic of investigation to elucidate the mechanisms involved in this process (Brogdon and McAllister, 1998). The increase in lethal concentration (LC) of pesticides in arthropod populations is a strong indication of the presence of resistance in these populations (Wharton and Roulston, 1970; CossíoBayúgar et al., 2009; Ranson et al., 2002).

The detoxification of xenobiotics is an essential life function and is carried out by three specific enzyme families: glutathione $S$ transferases, esterases (or carboxylesterases) and cytochrome P450 s (CYPs) (Hemingway and Ranson, 2000; Hemingway et al., 2004; Li et al.,

\footnotetext{
* Corresponding author.

E-mail address: luciana.gatto@embrapa.br (L.G. Brito).
} 
2007; Russel et al., 2011). Measuring the activity of these enzymes in natural arthropod populations is an important step in monitoring insecticide resistance mechanisms and should be conducted together with the surveillance of control efficacy to prevent significant changes in susceptibility to the pesticides being used (Brogdon, 1989; Brogdon and McAllister, 2004; Coleman and Hemingway 2007; Polson et al., 2011).

The OP pesticides exert their main toxicological effects through nonreversible phosphorylation of esterases in the central nervous system. The acute toxic effects are related to inhibition of acetylcholinesterases (AChEs). The inhibition of these enzymes causes over-stimulation of nicotinic and muscarinic acetylcholine receptors (Abdollahi et al., 2004). The complex mechanisms by which $R$. microplus develops resistance to OPs seems to involve dominant resistant alleles, gene copy number, transcript expression level, and splice variants in genes encoding specific enzyme families involved in the metabolism of this chemical group (Baxter and Barker, 1998; Hernandez et al., 1999; Baxter and Barker, 2002; Temeyer et al., 2004, 2007; Bendele et al., 2015; Graham et al., 2016; Jyoti et al., 2016; Robbertse et al., 2016). Baxter and Baker (1998) found evidence that the establishment and maintenance of resistance occurs through a complex multifactorial process involving the esterase family of enzymes, especially AChEs. One or more AChEs appear to be involved in the response to pesticides (Baffi et al., 2008; Temeyer et al., 2010, 2013).

The use of phenotypic bioassays to identify pesticide susceptibility is still the most common method to diagnose resistance in $R$. microplus populations. However, the speed and accuracy of techniques based on polymerase chain reaction (PCR) can help keep pesticides as effective tools for pest control in cattle herds. Molecular methods are suitable to detect the resistance response when it is influenced by gene expression. The quantitative polymerase chain reaction (qPCR) technique makes it possible to identify changes in the metabolic pattern related to pesticide action. One of the most important applications of qPCR in real time is in messenger ribonucleic acid (mRNA) expression studies, which can quantify the number of copies of complementary deoxyribonucleic acid (cDNA) or genomic DNA (Ginzinger, 2002).

New compounds are not being introduced at the same speed that pesticide resistance in populations of $R$. microplus is developing. Because of that, early diagnosis of resistance in tick populations can facilitate the most appropriate use of the chemical groups available. The aim of the present study was to develop a qPCR assay to detect carboxylesterases, specifically $\mathrm{AChE}_{2}$ and $\mathrm{EST}_{1}$, enzymes involved in OP metabolism in arthropod parasites, more specifically in the cattle tick R. microplus. Quantification of these individual components will allow detecting the increase in the metabolic production of these enzymes in OP-resistant $R$. microplus populations. Finally, the results of this study will also aid in diagnosing resistance in cattle tick populations, which is an important step for rational selection of effective chemical control, and together with better management strategies will improve tick control.

\section{Material and methods}

\subsection{Characterization of Rhipicephalus microplus strain and phenotypic analysis}

Two field populations of $R$. microplus were previously identified by the larval packet test (LPT) according to Stone and Haydock (1962) as OP-sensitive (Pirajuí strain, $\mathrm{LC}_{50}=0.13 \mu \mathrm{g} / \mathrm{cm}^{2}$ ) and the other OPresistant (Presidente Médici strain, $\mathrm{LC}_{50}=8.14 \mu \mathrm{g} / \mathrm{cm}^{2}$ ). The larvae were obtained from engorged females collected from the Pirajuí and Presidente Médici populations and were incubated in a biological oxygen demand (BOD) chamber at $25{ }^{\circ} \mathrm{C}$ with $75-80 \%$ humidity for oviposition and larval production. Briefly, about 100 larvae, with ages between 14 and 18 days, were placed between two sheets of filter paper $(2 \times 2 \mathrm{~cm})$ previously moistened with diazinon solutions (analytical standard, 99.0\%, Chem Service, Lot 2221-100) at concentrations of $3.2 \mu \mathrm{g} / \mathrm{cm}^{2}, 0.8 \mu \mathrm{g} / \mathrm{cm}^{2}, 0.2 \mu \mathrm{g} / \mathrm{cm}^{2}, 0.05 \mu \mathrm{g} / \mathrm{cm}^{2}$ and $0.013 \mu \mathrm{g} / \mathrm{cm}^{2}$. All concentrations were tested in triplicate as well as the control treatment, which was performed using acetone (ACS reagent, $\leq 99.5 \%$, Sigma-Aldrich, Lot BCBG9126 V). The numbers of dead and living larvae were counted after $24 \mathrm{~h}$ under a stereoscopic microscope with the aid of a vacuum pump attached to a pipette. Larvae that were totally immotile were considered dead. The lethal concentrations were calculated by statistical analysis using the Probit procedure of the SAS program (SAS, 2003).

To promote enzyme detoxification, which is responsible for tick survival when resistant strains of $R$. microplus are exposed to OP pesticides, the adult immersion test (AIT) was performed. Groups of 10 females of the Presidente Médici strain, obtained from the $R$. microplus larvae that survived exposure to different concentrations of Diazinon in LPT, were immersed in diazinon solutions (analytical standard, 99.0\%, Chem Service, Lot 2221-100) at concentrations of $1.0 \mathrm{mg} / \mathrm{ml} \quad(1000 \mathrm{ppm}), 2.5 \mathrm{mg} / \mathrm{ml} \quad(2500 \mathrm{ppm})$, and $5.0 \mathrm{mg} / \mathrm{ml}$ (5000 ppm). All concentrations were tested in triplicate as well as the control treatment, which was performed using ultrapure water. Engorged females remained immersed with constant stirring for $30 \mathrm{~min}$ and then were dried on paper towels and allocated to Petri dishes kept in a BOD chamber at $25^{\circ} \mathrm{C}$ with $75-80 \%$ humidity. Mortality results were noted after $24 \mathrm{~h}$ and surviving females were dissected under phosphate-buffered saline $\mathrm{pH}=7.4$ to remove the upper third of the tick, where the synganglion, the tick central nervous system, is located. Dissected tissues were then placed in RNALater (Ambion, Austin, TX, USA) according to the manufacturer's protocol.

\subsection{Total RNA isolation and cDNA synthesis}

Total RNA was extracted from the upper third of individual females from the Presidente Medici strain that survived the exposure to the highest concentration of diazinon and from pool of larvae (100 larvae), as well as from the Pirajuí strain that died when exposed to the highest concentration of diazinon in the LPT. For that, the SV Total RNA Isolation System (Promega Corporation, REF Z3100, USA) was used in accordance to the manufacturer's recommendations. The total concentrations of extracted RNA, purity and integrity were evaluated with the RNA 6000 Nano Assay kit using an Agilent 2100 Bioanalyzer Microfluidic System (Agilent Technologies Inc., Germany). Before transcription, total RNA was treated with the DNase I kit (Life Technologies, USA) following the manufacturer's recommendations.

For cDNA synthesis, we used the Anchored Oligo random primer (dT) 23 (Sigma-Aldrich, USA) in an incubation reaction at $70{ }^{\circ} \mathrm{C}$ for 10 min together with the treated total RNA, as described by the manufacturer. Then we performed the reverse transcription (RT) reaction using the High-Capacity cDNA kit (Applied Biosystems, USA) according to the protocol described by the manufacturer, in a final volume of $20 \mu \mathrm{L} /$ reaction. Finally, the synthesized cDNA was quantified by spectrophotometry to assess the RT reaction efficiency. The genomic-DNA contamination was measured with RT(-) controls, which were performed with no added reverse transcriptase in the samples.

\subsection{Design of specific primers}

The nucleotide database with GenBank accession codes AF067771. 1, AJ278342.1, AJ278345.1, DQ533868.1 and AF286096.1 allowed obtaining sequences deposited in the GenBank the primers to detect the transcripts involved in synthesizing enzymes that confer resistance to OP in the cattle tick.

We aligned the sequences using the Clustal-W algorithm (DNAStar Inc., Madison, WI, USA) to identify conserved regions. The primers were obtained with the Primer Blast software (Ye et al., 2012), and the annealing temperature $(\mathrm{Tm})$ was the selective parameter to choose primers. The theoretical $\mathrm{Tm}$ of the amplicons for each primer was 
estimated using the same software. Design of the primers for the $18 \mathrm{~S}$ ribosomal RNA gene from $R$. microplus was done using the sequence with GenBank accession code JX051005.1. For use in qPCR assay, primers were designed (Table 2) and the amplicons selected had Tm values ranging from $80^{\circ} \mathrm{C}$ to $87.5^{\circ} \mathrm{C}$ so they could be identified in the qPCR assay.

\section{4. $q P C R$ reactions}

Quantitative PCR studies were designed according to the MIQE guidelines (Bustin et al., 2009). Quantitative polymerase chain reactions (qPCR) were run on all genes to determine optimal reaction conditions, PCR efficiencies, and optimal reagent concentrations. The qPCR reactions were carried out with the CFX 96 Real-Time PCR Detection System from BioRad. All primers were designed to detect and quantify the transcripts involved in the synthesis of different AChEs and ESTs of $R$. microplus. The amplicons obtained from these designed primers varied from 82 to 150 base pairs. As proposed by Saldivar et al. (2008), the 18S ribosomal RNA gene of $R$. microplus was used for normalization in the gene expression study. Singleplex real-time PCR assays for each primer were performed using a final volume of $20 \mu \mathrm{L}$, with 2X SsoFast EvaGreen ${ }^{\circ}$ Supermix ${ }^{\mathrm{TM}}$ (Bio-Rad Laboratories Inc., USA), $100 \mathrm{ng}$ of cDNA and $0.5 \mathrm{uM}$ of each primer. The PCR conditions consisted of an initial denaturation step at $95{ }^{\circ} \mathrm{C}$ for $90 \mathrm{~s}, 39$ cycles at $95{ }^{\circ} \mathrm{C}$ for $5 \mathrm{~s}, 60^{\circ} \mathrm{C}$ for $20 \mathrm{~s}$ and $72{ }^{\circ} \mathrm{C}$ for $30 \mathrm{~s}$, followed by a final cooling to $4{ }^{\circ} \mathrm{C}$ with unlimited time. All samples were run in triplicate and both no-template and no-reverse transcriptase controls were utilized to verify DNA-free status of the negative control samples.

\subsection{Construction of calibration curve and quantification of the number of copies}

To estimate the number of DNA copies (NC), calibration curves were standardized with cDNA amplicons from $R$. microplus strain Presidente Medici, which were amplified with the selected primers, and the $18 \mathrm{~S}$ ribosomal RNA gene of $R$. microplus was used for qPCR normalization. The cDNA template was quantified in a NanoDrop ND-1000 spectrophotometer (Thermo Scientific, Wilmington, DE). Based on the known value, each cDNA sample was diluted in series $\left(10^{-10}-10^{-1}\right)$ and the quantification ranges were determined for each gene. The dilutions based on the calibration curve of each gene were submitted to the qPCR tests together with the samples and controls to estimate the NC of cDNA from AChEs and EST transcripts. The reaction efficiency (E) (Pfaffl, 2001; Vandesompele et al., 2002), expressed as a percentage, was determined by the following formula:

$\left.\% \mathrm{E}=\left(10^{-1 / \text { Slope }}\right)-1\right) * 100$

where:Slope $=$ slope of the derivative (tangent line) of the calibration curve

The NC of molecules from the target cDNA at each dilution was calculated by the formula described by Ke et al. (2006): NC $(\mu \mathrm{L})=$ $\left[\left(6.022 \times 10^{23}\right.\right.$ (copies $\left./ \mathrm{mol}\right) \times$ concentration $(\mathrm{g} / \mathrm{mol}) /$ molecular mass $(\mathrm{g} / \mu \mathrm{L})]$, where $6.022 \times 10^{23}$ is Avogadro's number and the molecular mass is the average molecular weight of the molecule from the double strand nucleotide $(330 \times 2)$ multiplied by the size of the fragment. The NC values found in the dilutions from the calibration curves were used to establish a regression equation allowing estimation of the NC values for the DNA from AChE and EST genes for each sample. The software that comes with the BioRad CFX96 system performed these analyses. Samples that presented a standard deviation greater than 0.5 of the quantitative cycle $(\mathrm{Cq})$ in relation to one of the triplicates were analyzed again.

The melting curve was standardized from a variable annealing temperature ramp from $60{ }^{\circ} \mathrm{C}$ to $80^{\circ} \mathrm{C}$ with an increase of $2{ }^{\circ} \mathrm{C} / \mathrm{s}$. The relative expression data were analyzed using the CFX Manager ${ }^{\mathrm{TM}}$ software. Triplicates of all samples were used to evaluate the reproducibility of each molecular target.

\subsection{Cloning and sequencing of the samples}

cDNA samples were amplified with the primers LGB 003, LGB 007 and LGB 12 under the following conditions: $100 \mathrm{ng}$ of cDNA $(2 \mu \mathrm{L})$ was added to GoTaq DNA polymerase buffer at $1 \mathrm{x}, 0.2 \mathrm{mM}$ of dNTPs, $0.4 \mu \mathrm{M}$ of each oligonucleotide, $5 \mathrm{U}$ of GoTaq DNA polymerase (Promega), and ultrapure water in a final volume of $50 \mu \mathrm{L}$. The reactions were performed in an Arktik ${ }^{\mathrm{TM}}$ thermal cycler (Thermo Scientific, Waltham, MA, USA) under the following conditions: initial denaturing at $95^{\circ} \mathrm{C}$ for $2 \mathrm{~min}$, followed by 30 cycles at $95^{\circ} \mathrm{C}$ for $1 \mathrm{~min}$ each, $60{ }^{\circ} \mathrm{C}$ for $1 \mathrm{~min}, 72{ }^{\circ} \mathrm{C}$ for $1 \mathrm{~min}$, and final extension at $72{ }^{\circ} \mathrm{C}$ for $5 \mathrm{~min}$, to obtain the amplicons. These were visualized in $2.5 \%$ agarose gel stained with GelRed $^{\mathrm{TM}}$ (Biotium Inc., Fremont, CA, USA). The specific PCR products were excised from the gel and the cDNA was extracted from the agarose gel using the PureLink ${ }^{\mathrm{TM}}$ Quick Gel Extraction kit (Invitrogen, Carlsbad, CA, USA). The PCR products were linked to the pGEM-T Easy vector, utilizing the pGEM ${ }^{\circ}$-T Easy Vector System I kit (Promega, Madison, WI, USA), according to the manufacturer's recommendations, with a molecular ratio of $4: 1$, at $4{ }^{\circ} \mathrm{C}$ for $16 \mathrm{~h}$. Chemically competent $E$. coli XL-10 gold cells were transformed with $5 \mu \mathrm{l}$ of the PGEM $^{\oplus}$-transcript construction by the thermal shock method (Sambrook et al., 2001). The cells were plated on LB-agar containing $100 \mu \mathrm{g} / \mathrm{ml}$ of ampicillin, $100 \mu \mathrm{l}$ of IPTG $100 \mathrm{mM}$ and $20 \mu \mathrm{l}$ of X-gel $(50 \mathrm{mg} / \mathrm{ml})$, and were incubated at $37^{\circ} \mathrm{C}$ for $16 \mathrm{~h}$. The DNA of the selected clones was purified using the Wizard Plus SV Minipreps DNA Purification System kit (Promega, Madison, WI, USA), according to the manufacturer's recommendations.

The plasmid DNA of the E. coli clones containing the pGEM $^{\circ}$ transcript construction was purified using the Wizard Plus SV Minipreps DNA Purification System kit (Promega, Madison, WI, USA). The DNA sequences were obtained in an ABI Prism 3130 XL sequencer (Applied Biosystems Inc., Foster City, CA, USA), utilizing the BigDye Terminator v3.1 Cycle Sequencing kit (Applied Biosystems Inc.) with the forward primers LGB 003, LGB 007 and LGB 12. The sequences were analyzed regarding quality with the Phred program (http://www. bioinformatica.ucb.br/electro.htm). Sequence analysis was conducted using GenBank BLAST (Zhang et al., 2000).

\section{Results}

The engorged females from the Presidente Medici population showed an $\mathrm{LC}_{50}$ value of $6.7 \mathrm{mg} / \mathrm{ml}$ for diazinon in the AIT (Table 1). For LPT with Pirajuí and Presidente Medici strains, the $\mathrm{LC}_{50}$ values were, respectively, $0.13 \mu \mathrm{g} / \mathrm{cm}^{2}$ and $8.14 \mu \mathrm{g} / \mathrm{cm}^{2}$, yielding a resistance factor (RF) of 62.6 for the Presidente Medici population.

Initially, the real-time assays were optimized in singleplex PCR

Table 1

Mortality results of the adult immersion tests with different diazinon concentrations, conducted with Presidente Medici cattle tick population.

\begin{tabular}{llllll}
\hline Diazinon Concentration & Repetition & Alive & Dead & Total & Mortality (\%) \\
\hline $0.10 \%$ & 1 & 14 & 1 & 15 & 7 \\
$0.10 \%$ & 2 & 12 & 3 & 15 & 20 \\
$0.10 \%$ & 3 & 13 & 2 & 15 & 13 \\
$0.25 \%$ & 1 & 10 & 5 & 15 & 33 \\
$0.25 \%$ & 2 & 10 & 5 & 15 & 33 \\
$0.25 \%$ & 3 & 12 & 3 & 15 & 20 \\
$0.50 \%$ & 1 & 10 & 5 & 15 & 33 \\
$0.50 \%$ & 2 & 6 & 9 & 15 & 60 \\
$0.50 \%$ & 3 & 9 & 6 & 15 & 36 \\
Control & 1 & 15 & 0 & 15 & 0 \\
Control & 2 & 15 & 0 & 15 & 0 \\
Control & 3 & 15 & 0 & 14 & 0 \\
\hline
\end{tabular}


Table 2

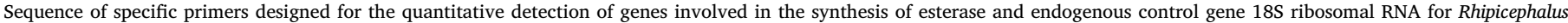
microplus populations.

\begin{tabular}{|c|c|c|c|c|}
\hline Primer & Sequence of Oligonucleotides $\left(5^{\prime}-3^{\prime}\right)$ & Transcript & Amplicon & $\operatorname{Tm}^{*}$ \\
\hline LGB 001 For & CCGTTGGTATTTGGCAGAGT & Putative acetylcholinesterase 2 & $102 \mathrm{pb}$ & $60{ }^{\circ} \mathrm{C}$ \\
\hline LGB 001 Rev & TCCTTTGGCAAAATCACTCC & & & \\
\hline LGB 002 For & GCTTTTGGAAACGTTGTGGT & & $143 \mathrm{pb}$ & $60{ }^{\circ} \mathrm{C}$ \\
\hline LGB 002 Rev & GCAGCAATGTTTTCCTGGAT & & & \\
\hline LGB 003 For & CTGCCATACGATCAGCAGAA & & $124 \mathrm{pb}$ & $60{ }^{\circ} \mathrm{C}$ \\
\hline LGB 003 Rev & ATCCTTCTTGGAAGCCACCT & & & \\
\hline LGB 004 For & GCCGATTCAAGGTCATTCAT & & $82 \mathrm{pb}$ & $59,9^{\circ} \mathrm{C}$ \\
\hline LGB 004 Rev & GTATCTTGCATCGTGGCTCA & & & \\
\hline LGB 005 For & TGCCGGTGATATGGACTACA & Acetylcholinesterase 2 (achE2 gene) & $109 \mathrm{pb}$ & $59,9^{\circ} \mathrm{C}$ \\
\hline LGB 005 Rev & AGCTGTGAACTTTGGCCACT & & & \\
\hline LGB 006 For & TGTGCCGGTGATATGGACTA & & $111 \mathrm{pb}$ & $59,9^{\circ} \mathrm{C}$ \\
\hline LGB 006 Rev & AGCTGTGAACTTTGGCCACT & & & \\
\hline LGB 007 For & CCGCAATACCTCTCGATGAT & Acetylcholinesterase 2 (achE2 gene) & $96 \mathrm{pb}$ & $60,1^{\circ} \mathrm{C}$ \\
\hline LGB 007 Rev & ACAGGAAACCGAATGACTGC & & & \\
\hline LGB 008 For & TTGCAGCTCCTTTTTGGACT & Rhipicephalus microplus carboxylesterase (EST9) & $132 \mathrm{pb}$ & $60^{\circ} \mathrm{C}$ \\
\hline LGB 008 Rev & ATTTGCCCGAACAGTAAACG & & & \\
\hline LGB 009 For & GTCTTGCAGCTCCTTTTTGG & & $135 \mathrm{pb}$ & $60{ }^{\circ} \mathrm{C}$ \\
\hline LGB 009 Rev & ATTTGCCCGAACAGTAAACG & & & \\
\hline LGB 010 For & CTTGCAGCTCCTTTTTGGAC & & $133 \mathrm{pb}$ & $60{ }^{\circ} \mathrm{C}$ \\
\hline LGB 010 Rev & ATTTGCCCGAACAGTAAACG & & & \\
\hline LGB 011 For & GGGTGACCTTGTTTGGAGAA & Rhipicephalus microplus esterase & $82 \mathrm{pb}$ & $59,9^{\circ} \mathrm{C}$ \\
\hline LGB 011 Rev & TTGAAGAGACCCTCGCTCAT & & & \\
\hline LGB 012 For & CAACATTGTAGGCTGCTCCA & & $150 \mathrm{pb}$ & $60^{\circ} \mathrm{C}$ \\
\hline LGB 012 Rev & ATGGGAGCGAAAGGAATCTT & & & \\
\hline LGB 013 For & AAGCAGAAGTGGCCAAGGTA & & $84 \mathrm{pb}$ & $60^{\circ} \mathrm{C}$ \\
\hline LGB 013 Rev & GAAACCCTTGGTCTCGTTGA & & & \\
\hline LGB 014 For & GGGTGACCTTGTTTGGAGAA & Rhipicephalus microplus acetylcholinesterase-like & $82 \mathrm{~PB}$ & $59,9^{\circ} \mathrm{C}$ \\
\hline LGB 014 Rev & TTGAAGAGACCCTCGCTCAT & & & \\
\hline LGB 015 For & AAGCAGAAGTGGCCAAGGTA & & $84 \mathrm{pb}$ & $60{ }^{\circ} \mathrm{C}$ \\
\hline LGB 015 Rev & GAAACCCTTGGTCTCGTTGA & & & \\
\hline LGB 016 For & GGCAAAGTGGTTCACGTTTT & & $126 \mathrm{pb}$ & $60^{\circ} \mathrm{C}$ \\
\hline LGB 016 Rev & AGTATCCGGCCAGCTTTTCT & & & \\
\hline RNA 18S For & AAAGCTGCTGCGGTTAAAAA & Rhipicephalus microplus $18 \mathrm{~S}$ ribosomal RNA gene & $131 \mathrm{pb}$ & $60{ }^{\circ} \mathrm{C}$ \\
\hline RNA 18S Rev & TCTCGAGGCACACAATGAAG & & & \\
\hline
\end{tabular}

"Tm - melting temperature.

assays using the Eva-Green ${ }^{\mathrm{Tm}}$ DNA binding dye (SoFast EvaGreen kit, BioRad). The primer pairs designed were tested for quantitative detection of AChE and EST transcripts, to ascertain the best performance for amplification of the selected molecular targets. To optimize the PCR, we used the lowest concentrations of primers and magnesium chloride $\left(\mathrm{MgCl}_{2}\right)$ able to generate the greatest fluorescence peaks and the lowest preliminary amplification cycles (threshold cycle - Ct). Also, we analyzed the resolution of the peaks of the melting curves and the quantification cycle values (Cq). The 18S ribosomal RNA gene of $R$. microplus was the normalization control gene to calculate the relative gene expression in samples from engorged females that survived the AITs.

After initial screening of transcripts, which was necessary to identify the best primer for each evaluated enzyme, three primers were selected for development of a qPCR assay to detect OP-resistant $R$. microplus ticks. The criteria used to choose these primers were related with the ability to discriminate the specific transcripts in qPCR. Distinct Tm peaks were obtained for each selected primer, these being $82.5^{\circ} \mathrm{C}$ and $80{ }^{\circ} \mathrm{C}$ for primers LGB 003 and LGB 007, respectively, which detect the synthesis of $\mathrm{AChE}_{2}$ transcripts; and $87.5^{\circ} \mathrm{C}$ for LGB 012 , which detects $\mathrm{EST}_{1}$ transcripts. The Tm of $83.5^{\circ} \mathrm{C}$ detects the $18 \mathrm{~S}$ ribosomal RNA endogenous control gene of $R$. microplus. Tm peaks identified in individual assays for transcripts involved in the synthesis of a putative $\mathrm{AChE}_{2}\left(\mathrm{pAChE}_{2}\right), \mathrm{AChE}_{2}$, and $\mathrm{EST}_{1}$ were also observed in post-PCR EvaGreen analysis (Fig. 1). The standard curves obtained from $\mathrm{Cq}$ values of singleplex real-time assays permitted detecting a linear correlation $\left(\mathrm{R}^{2} \geq 0.8\right)$ between the $\mathrm{Cq}$ values and the $\log _{10}$ of the number of copies of initial cDNA (Fig. 2). The nucleotide sequences obtained from the selected primers for the diagnosis of OP resistance in $R$. microplus by qPCR were deposited in the GenBank and received accession code numbers of KX357796 for the transcript associated with $\mathrm{pAChE}_{2}$, KX345141 for the $\mathrm{AChE}_{2}$ and KX357797, which corresponded to the $\mathrm{EST}_{1}$ transcript. Point mutations were observed in transcripts of $\mathrm{pAChE}_{2}$ and $\mathrm{AChE}_{2}$ in susceptible and resistant $\mathrm{OP}$. microplus populations when compared to the reference sequence used to design the primers (Figs. 3 and 4). No point mutation in the nucleotide base sequence related to the transcript that encoded the expression of $\mathrm{EST}_{1}$ was observed. Only overexpression of this enzyme in OP-resistant individuals was observed (Fig. 5).

There was a significant correlation between the phenotypic assays (AIT) and the increase in the number of transcripts involved in the synthesis of OP detoxifying enzymes. The analysis of the standard curves for the tested molecular targets showed a correlation coefficient $\left(\mathrm{R}^{2}\right)$ above 0.98 for all routes associated with metabolic detoxification of OP pesticides. The sequencing of the $\mathrm{pAChE}_{2}, \mathrm{AChE}_{2}$ and $\mathrm{EST}_{1}$ amplicons was able to identify the correct transcript of these enzymes in the Presidente Medici and Pirajui populations (Fig. 6).

\section{Discussion}

The cattle tick, $R$. microplus, is recognized as the most important ectoparasite of cattle in the world in terms of the economic losses (Guerrero et al., 2006). Potential economic losses caused by cattle tick in Brazilian cattle herds were estimated at around US\$ 3.24 billion per 


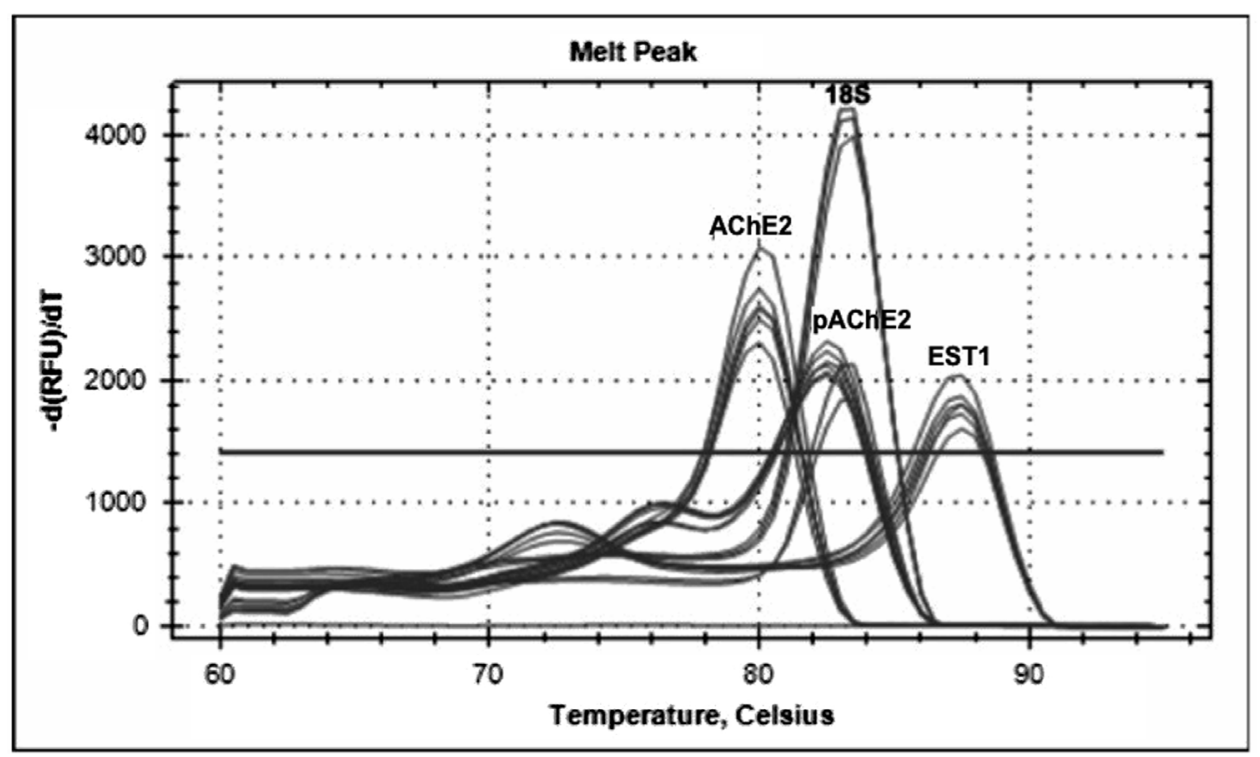

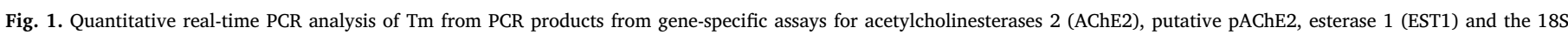
ribosomal RNA normalization reference gene (18S). The graph was generated by $\mathrm{CFX}^{\mathrm{TM}}$ Manager.

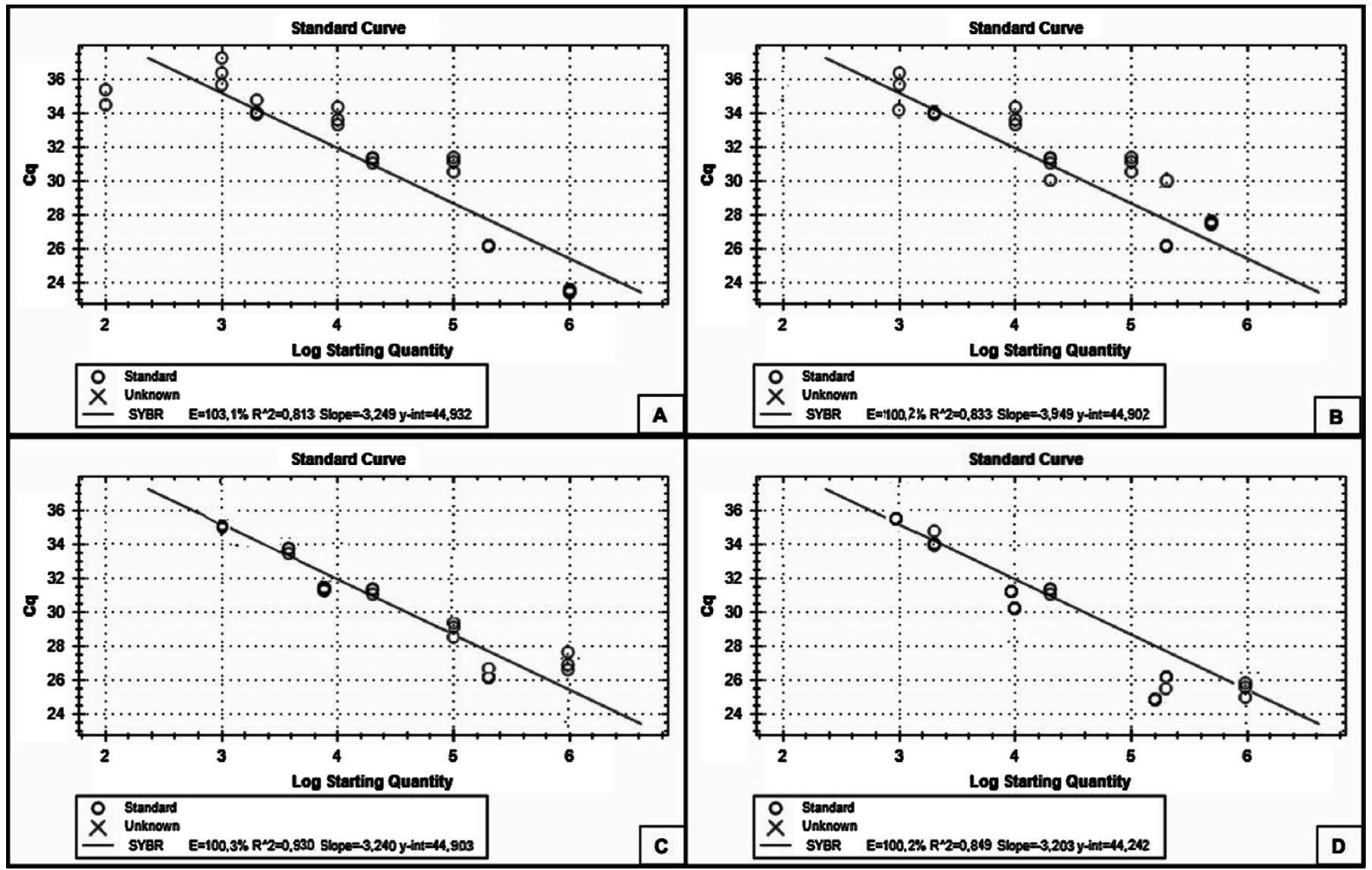

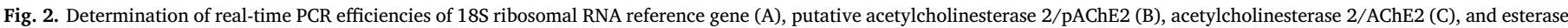
1/EST1 (D) for Rhipicephalus microplus. The graphs were generated by $\mathrm{CFX}^{\mathrm{TM}}$ Manager.

year (Grisi et al., 2014). The extensive problems with acaricide resistance in Brazilian R. microplus populations (Mendes et al., 2011; Brito et al., 2011; Higa et al., 2015) are caused both by heavy use of chemical pesticides and by the favorable climatic conditions, so that a significant number of herds have infestations during most months of the year, making cattle tick control a priority in Brazil.

Different mechanisms of OP resistance in arthropods can result from target-site insensitivity, reduced penetration through the cuticle and/or detoxification and/or sequestration by metabolic enzymes (Villatte et al., 2000). In order to verify the involvement of AChE, especially $\mathrm{AChE}_{2}$ and $\mathrm{EST}_{1}$, in detoxification of diazinon in susceptible and resistant Brazilian strains of $R$. microplus, a quantitative molecular assay was successfully developed to verify the increase of AChE levels in OP-resistant strain when it is compared with a susceptible strain, as 


\begin{abstract}
NCBI AF067771.1* CTGCCATACGATCAGCAGAAAAGCGAGGACTGCCTTTACTGACACCGAGG
NCBI KX357796**

Susceptible

NCBI AF067771.1* CTGAACACGTCAGCAGGGCTCCCAGTGATGGCCTGGATTCACGGAGGTGG

NCBI KX357796*t $\quad$. . . . . . . . . . . . . . . . . . . . . . . . . .

Susceptible strain

A..........

NCBI AF067771.1* CTTCCAAGAAGGAT

NCBI KX357796* $\ldots \ldots \ldots \ldots \ldots \ldots$

Susceptible strain $\ldots \ldots \ldots \ldots \ldots \ldots$

"NCBI AF067771.1 (Boophilus microplus putative acetylcholinesterase mRNA) represents the reference strain used for design LGB003 primer to OP resistance diagnostic by molecular quantitative assay, and *NCBI KX35796 is the transcripts sequences of cattle tick pAChE2 obtaneld by the cattle tick OP resistant strain.
\end{abstract}

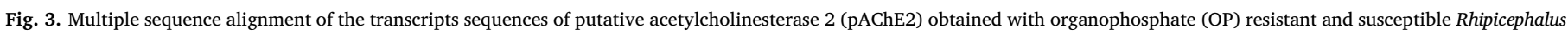
microplus populations.

NCBI AJ278345.1* CCGCAATACCTCTCGATGATGGAACTTATTTGGCTGCTTTTGGAAACG

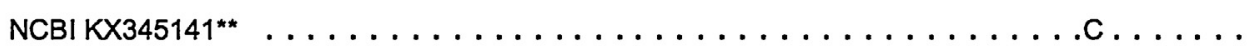

Susceptible strain

NCBI AJ278345.1* TTGTGGTGGTGACCATCGCATACAGGTTGCAGTCATTCGGTTTCCTGT

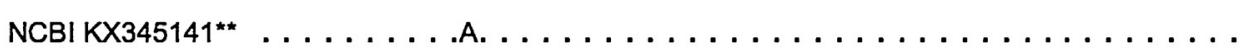

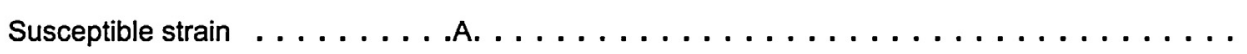

*NCBI AJ278345.1 (Boophilus microplus mRNA for acetylcholinesterase 2 (AChE2 gene, Ultimo strain) represents

the reference strain used for design LGB007 primer to OP resistance diagnostic by molecular quantitative assay and

**NCBI KX35141 is the transcripts sequences of cattle tick AChE2 obtaneid by the cattle tick OP resistant strain.

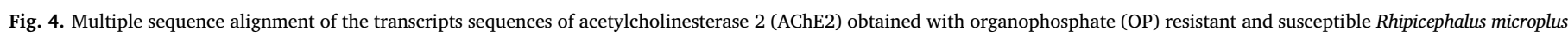
populations.

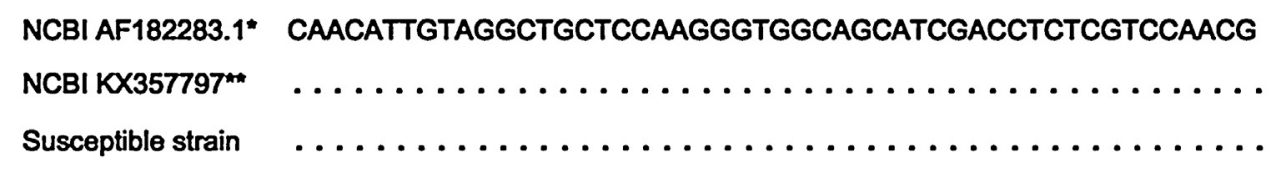

NCBI AF182283.1* CCGAAGAGATCGTCGACTGCTTCCGCAAGAAGTCCGCCGACGAGCTCGTG

NCBI KX357797"*

Susceptible strain

\title{
NCBI AF182283.1* AAGGCGGCCGCAGAGAGCGTGGCCCCCAAGAAGATTCCTTTCGCTCCCAT
} NCBI KX357797"*

Susceptible strain

-NCBI AF182283.1 (Rhip/cephalus microplus esterase mRNA) represents the reference strain used for design LGB012 primer to OP resistance diagnostic by molecular quantitative assay, and ${ }^{*} \mathrm{NCBI}$ KX357797 is the transcripts sequences of cattle tick EST1 obtaneld by the cattle tick OP resistant strain.

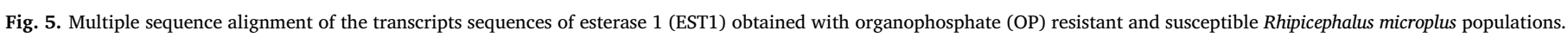




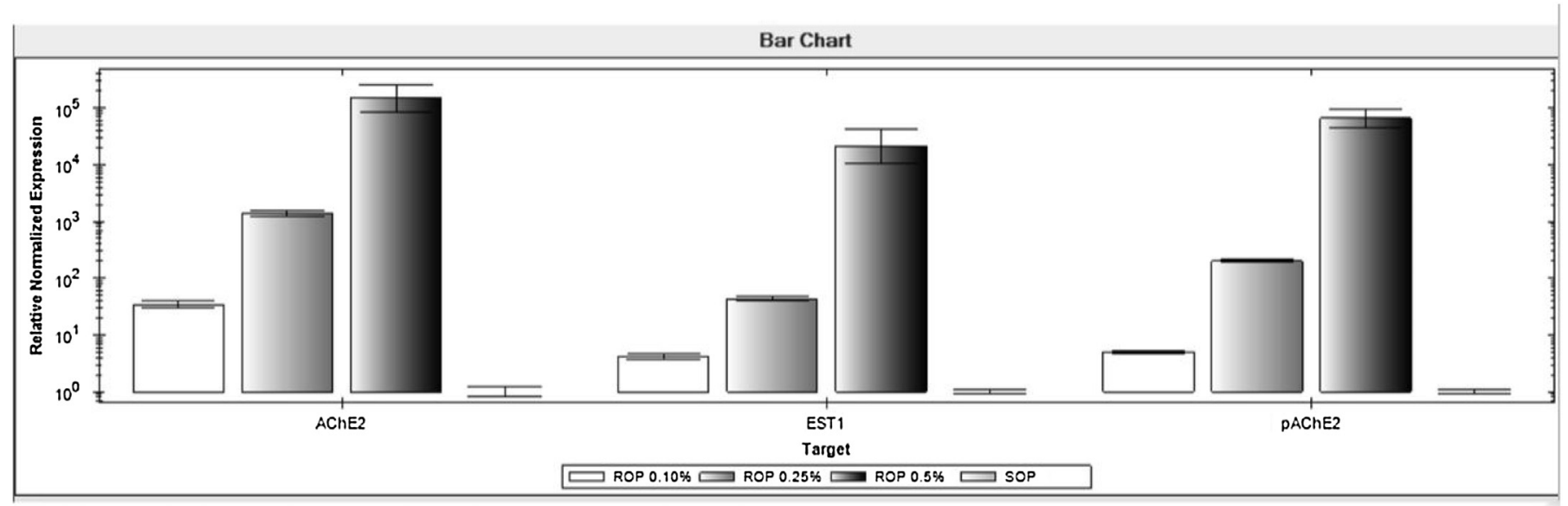

ROP - Resistant-organophosphate strain (Isolate Presidente Medici)

SOP - Susceptible-organophosphate strain (Isolate Pirajui)

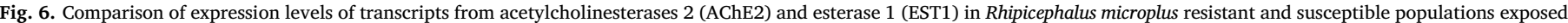
to different concentrations of organophosphate pesticide. The graph was generated by CFX ${ }^{\mathrm{TM}}$ Manager.

reported here.

Engorged females of R. microplus that survived after diazinon exposure were able to over-express AChE2 and EST1, which here was detected by qPCR, corroborating the phenotypic results. These significant increases in the cDNA level suggested a potential increase in enzyme activity (not tested). The over-expression in the transcripts involved in enzymatic syntheses of AChE2 and EST1 in the OP-resistant strain reported in this study was also observed by Van Leeuwen et al. (2010), who noted the involvement of various esterases in the resistance to pesticides in spotted spiders. A rise in the synthesis of the esterase enzyme family provides strong evidence that this mechanism involved in OP pesticide resistance is present (Baffi et al., 2008; Temeyer et al., 2010; Bellgard et al., 2012; Jyoti et al., 2016; Robbertse et al., 2016).

OP resistance appears to be mediated by epigenetic mechanisms, which can change the function of the genome under the influence of xenobiotics such as OP pesticides (Collotta et al., 2013). Baffi et al. (2008) reported that a malathion-resistant Brazilian strain of $R$. microplus had increased AChE levels compared to the susceptible strains, which was detected by qPCR in the resistant Presidente Medici strain. The occurrences of point mutations in the isolates evaluated appear not to be related with OP resistance, but show the inter- and intra-population variability. However, more studies need to be conducted to identify single nucleotide polymorphisms (SNPs), which can be used as acaricide resistance markers in ecetylcholinesterase and esterase genes.

The development of rapid diagnostic tests to detect resistance should be considered the foundation for establishing pesticide management strategies, as well the use of precision technologies aimed to control arthropod parasites (Pang, 2007; Pang et al., 2009; RosarioCruz et al., 2009). Accurate diagnostic tools need to be incorporated in pesticide management for tick control, especially in areas where there is no evident seasonal behavior of $R$. microplus, like in tropical regions.

\section{Conclusion}

A rise in the synthesis of the esterase enzyme family provides strong evidence that a $R$. microplus population is resistant to OP pesticides, and the qPCR assay can detect an increase in the cholinesterase and esterase transcript in OP-resistant cattle tick strains, also detected by fluctuations in the levels of the AChE and EST transcripts in engorged females exposed to varying concentrations of diazinon. These results shed light on OP resistance in $R$. microplus, but future studies are necessary to understand the influence of epigenetic mechanisms involved in the detoxification of $\mathrm{OP}$ pesticides.

\section{Acknowledgments}

We acknowledge the financial support of this project given by the Brazilian Agricultural Research Corporation (Embrapa: SEG/ 02.10.06.017.00.00), as well as the technical support provided by $\mathrm{Dr}$ Felix Guerrero, researcher of Knipling-Bushland U.S. Livestock Insects Research Laboratory - Agricultural Research Service/United States Department of Agriculture.

\section{References}

Abdollahi, M., Ranjbar, A., Shadnia, S., Nikfar, S., Rezaie, A., 2004. Pesticides and oxidative stress: a review. Med. Sci. Monit. 10, 141-147.

Baffi, M.A., de Souza, G.R.L., de Sousa, C.S., Ceron, C.R., Bonetti, A.M., 2008. Esterase enzymes involved in pyrethroid and organophosphate resistance in a Brazilian population of Riphicephalus (Boophilus) microplus (Acari, Ixodidae). Mol. Biochem. Parasitol. 160, 70-73.

Baxter, G.D., Barker, S.C., 1998. Acetylcholinesterase cDNA of the cattle tick, Boophilus microplus: characterisation and role in organophosphate resistance. Insect Biochem. Mol. Biol. 28, 581-589.

Baxter, G.D., Barker, S.C., 2002. Analysis of the sequence and expression of a second putative acetylcholinesterase cDNA from organophosphate-susceptible and organophosphate-resistant cattle ticks. Insect Biochem. Mol. Biol. 32, 815-820.

Bellgard, M.I., Moolhuijzen, P.M., Guerrero, F.D., Schibeci, D., Rodriguez-Valle, M., Peterson, D.G., Dowd, S.E., Barrero, R., Hunter, A., Miller, R.J., Lew-Tabor, A.E., 2012. CattleTick Base: an integrated internet-based bioinformatics resource for Rhipicephalus (Boophilus) microplus. Int. J. Parasitol. 42, 161-169.

Bendele, K., Guerrero, F., Miller, R., Li, A., Barrero, R., Moolhuijzen, P., Black, M., McCooke, J., Meyer, J., Hill, C., Bellgard, M., 2015. Acetylcholinesterase 1 in populations of organophosphate-resistant North American strains of the cattle tick, Rhipicephalus microplus (Acari: ixodidae). Parasitol. Res. 114, 3027-3040.

Brito, L.G., Barbieri, F.S., Rocha, R.B., Oliveira, M.C.S., Ribeiro, E.S., 2011. Evaluation of the efficacy of acaricides used to control the cattle tick, Rhipicephalus microplus, in dairy herds raised in the Brazilian southwestern amazon. Vet. Med. Int (Article ID 806093, 6 pages).

Brogdon, W.G., McAllister, J.C., 2004. Insecticide resistance and vector control. J. Agromedicine 9, 329-345.

Brogdon, W.G., 1989. Biochemical resistance detection: an alternative to bioassay. Parasitol. Today 5, 56-60.

Bustin, S.A., Benes, V., Garson, J.A., Hellemans, J., Huggett, J., Kubista, M., Mueller, R., Nolan, T., Pfaffl, M.W., Shipley, G.L., Vandesompele, J., Wittwer, C.T., 2009. The MIQE guidelines: minimum information for publication of quantitative real-time PCR experiments. Clin. Chem. 55, 611-622.

Coleman, M., Hemingway, J., 2007. Insecticide resistance monitoring and evaluation in disease transmitting mosquitoes. J. Pest. Sci. 32, 69-76.

Collotta, M., Bertazzi, P. a., Bollati, V., 2013. Epigenetics and pesticides. Toxicology 307, 35-41. http://dx.doi.org/10.1016/j.tox.2013.01.017.

Cossío-Bayúgar, R., Miranda-Miranda, E., Portilla-Salgado, D., Osorio-Miranda, J., 2009. Quantitative PCR detection of cholinesterase and carboxylesterase expression levels in acaricide resistant Rhipicephalus (Boophilus) microplus. J. Entomol. 6 (117), 123. 
Ginzinger, D.G., 2002. Gene quantification using real-time quantitative PCR. Exp. Hematol. 30, 503-512.

Graham, K.M., Sparagano, O.A.E., Finn, R.D., 2016. Isolation of the monooxygenase complex from Rhipicephalus (Boophilus) microplus - clues to understanding acaricide resistance. Ticks Tick Borne Dis. 7, 614-623.

Grisi, L., Leite, R.C., Martins, J.R., Barros, A.T., Andreotti, R., Cançado, P.H.D., Léon, A.A.P., Pereira, J.B., Villela, H.S., 2014. Reassessment of the potential economic impact of cattle parasites in Brazil. Braz. J. Vet. Parasitol. 23, 150-156.

Guerrero, F.D., Nene, V.M., George, J.E., Barker, S.C., Willadsen, P., Entomol, J.M., 2006. Sequencing a new target genome: the Boophilus microplus (Acari: ixodidae) genome project. J. Med. Entomol. 43, 9-16.

Hemingway, J., Ranson, H., 2000. Insecticide resistance in insect vectors of human disease. Annu. Rev. Entomol. 45, 371-391.

Hemingway, J., Hawkes, N.J., McCarroll, L., Ranson, H., 2004. The molecular basis of insecticide resistance in mosquitoes. Insect Biochem. Mol. Biol. 34, 653-665.

Hernandez, R., He, H., Chen a, C., Ivie, G.W., George, J.E., Wagner, G.G., 1999. Cloning and sequencing of a putative acetylcholinesterase cDNA from Boophilus microplus (Acari: ixodidae). J. Med. Entomol. 36, 764-770.

Higa, L.O.S., Garcia, M.V., Barros, J.C., Koller, W.W., Andreotti, R., 2015. Acaricide resistance status of the Rhipicephalus microplus in Brazil: a literature overview. Med. Chem. 5, 326-333.

Jyoti, Singh, N.K., Singh, H., Rath, S.S., 2014. Malathion resistance in Rhipicephalus (Boophilus) microplus from Ludhiana district, Punjab. J. Parasit. Dis. 38, 343-346.

Jyoti, Singh, N.K., Singh, H., Singh, N.K., Rath, Shitanshu S., 2016. Multiple mutations in the acetylcholinesterase 3 gene associated with organophosphate resistance in Rhipicephalus (Boophilus) microplus ticks from Punjab, India. Vet. Parasitol. 216, 108-117.

Ke, G.M., Cheng, H.L., Ke, L.Y., Ji, W.T., Chulu, J.L., Liao, M.H., Chang, T.J., Liu, H.J., 2006. Development of a quantitative Light cycler real-time RT-PCR for detection of avian reovirus. J. Virol. Methods 133, 6-13.

Li, A., Guerrero, F., Pruett, J., 2007. Involvement of esterases in diazinon resistance and biphasic effects of piperonyl butoxide on diazinon toxicity to Haematobia irritans irritans (Diptera: muscidae). Pestic. Biochem. Physiol. 87, 147-155.

Mendes, M.C., Lima, C.K.P., Nogueira, A.H.C., Yoshihara, E., Chiebao, D.P., Gabriel, F.H.L., Ueno, T.E.H., Namindome, A., Klafke, G.M., 2011. Resistance to cypermethrin, deltamethrin and chlorpyriphos in populations of Rhipicephalus (Boophilus) microplus (Acari: ixodidae) from small farms of the state of São Paulo. Brazil. Vet. Parasitol. 178, 383-388.

Miller, R.J., Davey, R.B., George, J.E., 2005. First report of organophosphate-resistant Boophilus microplus (Acari: ixodidae) within the United States. J. Med. Entomol. 42, 912-917.

Pang, Y.P., Ekström, F., Polsinelli, G. a., Gao, Y., Rana, S., Hua, D.H., Andersson, B., Andersson, P.O., Peng, L., Singh, S.K., Mishra, R.K., Zhu, K.Y., Fallon, A.M., Ragsdale, D.W., Brimijoin, S., 2009. Selective and irreversible inhibitors of mosquito acetylcholinesterases for controlling malaria and other mosquito-borne diseases. PLoS One 4, e6851.

Pang, Y.P., 2007. Species marker for developing novel and safe pesticides. Bioorg. Med. Chem. Lett. 17, 197-199.

Pfaffl, M.W., 2001. A new mathematical model for relative quantification in real-time RTPCR. Nucleic Acids Res. 29, 2002-2007.

Polson, K.A., Brogdon, W.G., Rawlins, S.C., Chadee, D.D., 2011. Characterization of insecticide resistance in Trinidadian strains of Aedes aegypti mosquitoes. Acta Trop.
$117,31-38$.

Ranson, H., Claudianos, C., Ortelli, F., Abgrall, C., Hemingway, J., Sharakhova, M.V., Unger, M.F., Collins, F.H., Feyereisen, R., 2002. Evolution of supergene families associated with insecticide resistance. Science 298, 179-181.

Robbertse, L., Baron, S., van der Merwe, N.A., Madder, M., Stoltsz, W.H., Maritz-Olivier, C., 2016. Genetic diversity, acaricide resistance status and evolutionary potential of a Rhipicephalus microplus population from a disease-controlled cattle farming area in South Africa. Ticks Tick Borne Dis. 7, 595-603.

Rosario-Cruz, R., Almazán, C., Miller, R.J., Dominguez-Garcia, D.J., Hernandez-Ortiz, R., de la Fuente, J., 2009. Genetic basis and impact of tick acaricide resistance. Front. Biosci. 14, 2657-2665.

Russel, R., Scott, C., Jakson, C.J., Pandey, G., Taylor, M.C., Choppin, C.W., Liu, J.-W., Oakeshott, J.G., 2011. The evolution of new enzyme function: lessons from xenobiotic metabolizing bacteria versus insecticide-resistant insects. Evol. Appl. 4, 225-248.

SAS Institute 2002-2003. Version 9 1. Cary, U.S.A.: SAS, 2003.

Sambrook, J., Maccallum, P., Russel, D., 2001. Molecular Cloning: A Laboratory Manual, 3nd ed. Cold Springs Harbour Press, NY, pp. p. 2344 (ISBN 0-87969-577-3).

Saldivar, L., Guerrero, F.D., Miller, R.J., Bendele, K.G., Gondro, C., Brayton, K.A., 2008. Microarray analysis of acaricide-inducible gene expression in the southern cattle tick, Rhipicephalus (Boophilus) microplus. Insect Mol. Biol. 17, 597-606.

Stone, B.F., Haydock, K.P., 1962. A method for measuring the acaricide-susceptibility of the cattle tick Boophilus microplus (Can.). Bull. Entomol. Res. 53, 563-578.

Temeyer, K.B., Davey, R.B., Chen, A.C., 2004. Identification of a third Boophilus microplus (Acari: ixodidae) cDNA presumptively encoding an acetylcholinesterase. J. Med. Entomol. 41, 259-268.

Temeyer, K.B., Pruett, J.H., Olafson, P.U., Chen, A.C., 2007. R86Q, a mutation in BmAChE3 yielding a Rhipicephalus microplus organophosphate insensitive acetylcholinesterase. J. Med. Entomol. 44, 1013-1018.

Temeyer, K.B., Pruett, J.H., Olafson, P.U., 2010. Baculovirus expression, biochemical characterization and organophosphate sensitivity of rBmAChE1, rBmAChE2, and rBmAChE3 of Rhipicephalus (Boophilus) microplus. Vet. Parasitol. 172, 114-121. http://dx.doi.org/10.1016/j.vetpar.2010.04.016.

Temeyer, K., Tuckow, A., Brake, D., Li, A., Pérez de León, A., 2013. Acetylcholinesterases of blood-feeding flies and ticks. Chem. Biol. Interact. 203, 319-322.

Van Leeuwen, T., Vontas, J., Tsagkarakou, A., Dermauw, W., Tirry, L., 2010. Acaricide resistance mechanisms in the two-spotted spider mite Tetranychus urticae and other important Acari: a review. Insect Biochem. Mol. Biol. 40, 563-572.

Vandesompele, J., De Preter, K., Pattyn, F., Poppe, B., Van Roy, N., De Paepe, A., Speleman, F., 2002. Accurate normalization of real-time quantitative RT-PCR data by geometric averaging of multiple internal control genes. Genome Biol. 3http://dx.doi. org/10.1186/gb-2002-3-7-research0034. (RESEARCH0034).

Villatte, F., Ziliani, P., Marcel, V., Menozzi, P., Fournier, D., 2000. A high number of mutations in insect acetylcholinesterase may provide insecticide resistance. Pestic. Biochem. Physiol. 67, 95-102.

Wharton, R., Roulston, W., 1970. Resistance of ticks to chemicals. Annu. Rev. Entomol. 15, 381-404.

Ye, J., Coulouris, G., Zaretskaya, I., Cutcutache, I., Rozen, S., Madden, T.L., 2012. PrimerBLAST: a tool to design target-specific primers for polymerase chain reaction. BMC Bioinf. 13, 134-145.

Zhang, Z., Schwartz, S., Wagner, L., Miller, W., 2000. A greedy algorithm for aligning DNA sequences. J. Comput. Biol. 7, 203-214. 